\title{
Pembenahan Lingkungan dan Pembuatan Bangunan yang Sehat, Kuat dan Nyaman di RW 10 Kelurahan Cawang
}

\author{
Lolom Evalita Hutabarat ${ }^{1}$, Efendy Tambunan ${ }^{2}$, Pinondang Simanjuntak ${ }^{3}$, Candra \\ Christanti Purnomo 4 \\ 1,2,3,4 Universitas Kristen Indonesia, Jakarta, Indonesia \\ E-mail: Lolom.Hutabarat@uki.ac.id; Efendy.Tambunan@uki.ac.id; \\ Pinondang.Simanjuntak@uki.ac.id; Candra.Christianti@uki.ac.id
}

\begin{abstract}
Abstrak
Penataan sistem Drainase dan Lingkungan di wilayah pemukiman pada penduduk yang ada di kota madya Jakarta Timur merupakan suatu kebutuhan yang sangat mendesak. Terlebih di masa pandemic COVID-19 yang telah berlangsung selama lebih dari 1 tahun, pembenahan lingkungan yang bersih, nyaman dan asri adalah salah satu cara untuk memutuskan mata rantai penyebaran penyakit tersebut. Keterbatasan lahan untuk zona hijau ataupun infrastrukur drainase dan trotoar jalan tentunya membutuhkan perencanaan secara optimal sesuai kriteria teknis sesuai standar yang ada untuk mendapatkan lingkungan perumahan yang sehat, aman dan nyaman bagi setiap penghuni. Untuk itu Program Studi Teknik Sipil UKI sebagai bagian dari masyarakat akademik yang berada di wilayah Kelurahan Cawang melalui Pengabdian kepada Masyarakat terlibat dalam memberikan pembekalan teknis dalam rangka penataan lingkungan dan hunian yang memenuhi standar di kawasan seperti ini.
\end{abstract}

Kata Kunci: sistem drainase; lingkungan aman dan nyamam

\begin{abstract}
Structuring the Drainage system and Environment in residential areas for residents in the municipalities of East Jakarta is a very urgent need. Especially during the COVID19 pandemic which has been going on for more than 1 year, improving a clean, comfortable and beautiful environment is one way to break the chain of spreading the disease. Limited land for green zones or drainage infrastructure and road sidewalks, of course, requires optimal planning according to technical criteria based on existing standards to get a healthy, safe and comfortable housing environment for every occupant. For this reason, the UKI Civil Engineering Study Program as part of the academic community in the Cawang Village area through Community Service involve in providing technical training in the context of environmental and residential arrangements that meet standards in areas like this.
\end{abstract}

Keywords:drainage system; safe and comfortable environment 


\section{PENDAHULUAN}

Kampus Universitas Kristen Indonesia berada di wilayah Cawang yang merupakan bagian dari wilayah administrasi Kecamatan Kramat Jati (Gambar 1) yang menaungi 7 Kelurahan termasuk kelurahan Cawang yang mencakup kawasan seluas $1,75 \mathrm{~km}^{2}$ atau $13,46 \%$ dari total wilayah Kecamatan
Kramat Jati yaitu $13 \mathrm{~km}^{2}$ (BPS, 2020). Sebagai wilayah yang termasuk dalam kategori padat menduduk, Kelurahan Cawang terdiri dari 12 RW dan 117 RT dengan jumlah penduduk mencapai 33.096 jiwa sesuai data statistik tahun 2020. Pertumbuhan jumlah penduduk di Kecamatan Kramat Jati selama 8 tahun terakhir dapat dilihat pada Tabel 1 berikut:

Tabel 1. Peningkatan Populasi Penduduk di Kecamatan Kramat Jati

\begin{tabular}{|c|c|c|c|c|c|c|c|c|}
\hline \multirow{2}{*}{ Kelurahan } & \multicolumn{8}{|c|}{ Jumlah Populasi Penduduk (jiwa) } \\
\hline & 2012 & 2013 & 2014 & 2015 & 2016 & 2017 & 2018 & 2019 \\
\hline $\begin{array}{l}\text { Bale } \\
\text { Kambang }\end{array}$ & 26.220 & 30.080 & 30.207 & 30.810 & 32.331 & 32.083 & 41.428 & 42.267 \\
\hline $\begin{array}{l}\text { Batu } \\
\text { Ampar }\end{array}$ & 36.164 & 50.953 & 51.667 & 52.406 & 54.027 & 53.797 & 62.609 & 63.606 \\
\hline $\begin{array}{l}\text { Kampung } \\
\text { Tengah }\end{array}$ & 37.652 & 49.290 & 48.650 & 49.326 & 50.704 & 50.444 & 51.429 & 51.356 \\
\hline Dukuh & 24.100 & 26.535 & 26.566 & 27.174 & 28.402 & 28.120 & 30.633 & 31.027 \\
\hline $\begin{array}{l}\text { Kramat } \\
\text { Jati }\end{array}$ & 38.280 & 39.217 & 38.837 & 39.093 & 40.098 & 39.577 & 32.718 & 32.544 \\
\hline Cililitan & 46.425 & 46.968 & 47.161 & 47.032 & 47.381 & 46.819 & 44.109 & 44.227 \\
\hline Cawang & 35.885 & 39.065 & 39.259 & 39.532 & 39.602 & 38.874 & 33.118 & 33.096 \\
\hline Total & 244.726 & 273.587 & 282.347 & 285.373 & 282.545 & 289.714 & 296.044 & 298.123 \\
\hline
\end{tabular}

Sumber: Kecamatan Kramat Jati Dalam Angka, 2020

Dari Tabel 1 dapat terlihat bahwa pertumbuhan penduduk secara keseluruhan di Kecamatan Kramat Jati meningkat dari tahun ke tahun dengan rata-rata laju pertumbuhan penduduk sebesar 2,9\% selama 8 tahun. Sedangkan khusus di wilayah Kelurahan Cawang peningkatan jumlah penduduk terbesar terjadi pada tahun 2013 (8,9\%) tetapi kemudian cenderung melambat bahkan sejak tahun 2016 terjadi penurunan jumlah penduduk dengan laju pengurangan penduduk rata-rata $5,6 \%$ sampai tahun 2019. Hal tersebut juga diperkirakan masih akan berlanjut mengingat situasi pandemik akibat penyebaran virus Covid-19 yang berlangsung sejak maret 2020 sampai saat ini karena telah banyak menelan korban jiwa khususnya bagi masyarakat yang berusia diatas 50 tahun.

Meskipun demikian, dengan kepadatan penduduk di Kelurahan Cawang sebesar 18.922 jiwa per $\mathrm{km}^{2}$ (2019) dengan kelompok usia terbanyak pada rentang 20-50 tahun, tetap memunculkan masalah pada lingkungan yaitu kebutuhan rumah hunian yang sehat, kuat dan nyaman. Terlebih dengan kondisi bencana 
banjir yang sering kali melanda Kelurahan

Cawang sehingga menimbulkan kerugian masyarakat secara materi. Bencana banjir hampir berulang setiap tahun sebagaimana yang baru-baru ini melanda RT 09, 10, 11, dan 12 di RW 5 Kelurahan Cawang, Kecamatan Kramat Jati Jakarta Timur di awal tahun 2021. Hal tersebut mengakibatkan terendamnya rumah warga hampir setinggi 1,5 $\mathrm{m}$ sehingga sebagian besar warga terpaksa mengungsi ke lokasi gedung kampus terdekat (metro.tempo.co, 8 Febuari 2021). Karena itu untuk meminimalisir dampak dari bencana banjir dan juga gempa yang seringkali melanda dibutuhkan pembinaan dan penataan menuju lingkungan yang lebih baik, ramah dan manusiawi serta rumah hunian yang sehat dan memiliki konstruksi yang kuat. Selain itu sarana pelayanan dasar seperti air bersih, saluran air limbah dan air hujan, pembuangan sampah umumnya kurang baik dan tidak beraturan. Perlu penataan permukiman yang lebih baik agar kawasan hunian di Kelurahan Cawang mendekati pola standar hunian yang layak.

Beberapa kawasan di daerah perkotaan yang padat penduduk seringkali secara fisik tidak layak menjadi kawasan dan hunian yang memenuhi standar. Pemerintah Provinsi DKI Jakarta berupaya melakukan penataan secara bertahap sejak tahun 2013 salah satunya melalui program Kampung Deret yang dituangkan dalam Pergub DKI No.64 Tahun 2013. Tujuan dari program ini adalah untuk menata permukiman kumuh menjadi permukiman yang bebas kumuh, sehat dan nyaman, juga meningkatkan peran serta dan tanggung jawab individu, keluarga atau masyarakat, serta meningkatkan kualitas hidup individu, keluarga, dan masyarakat melalui program bantuan yang diberikan oleh pemerintah untuk penataan kampung. Program ini sudah diimplementasikan di beberapa wilayah di Jakarta walaupun belum menyeluruh di semua pemukiman padat penduduk (Yani, 2014; Cahyani, 2019)

Berdasarkan data tahun 2012 jumlah rumah hunian yang ada di kotamadya Jakarta Timur berada diatas jumlah kepala keluarga (KK) kecuali di Kecamatan Matraman seperti terlihat pada Tabel 2 berikut:

Tabel 2. Perbandingan Jumlah Rumah dan KK di Kecamatan Kramat Jati

\begin{tabular}{lcc}
\hline \multicolumn{1}{c}{ Kecamatan } & Jumlah Rumah & Jumlah KK \\
\hline Pasar Rebo & 50.525 & 40.767 \\
Ciracas & 66.513 & 48.744 \\
Cipayung & 60.942 & 52.490 \\
Makasar & 47.811 & 34.660 \\
Kramat Jati & 71.218 & 55.867 \\
Jati Negara & 64.051 & 27.592 \\
Duren Sawit & 96.295 & 70.263 \\
\hline
\end{tabular}




\begin{tabular}{lcc}
\hline Cakung & 147.374 & 137.260 \\
Pulo Gadung & 67.208 & 34.845 \\
Matraman & 37.221 & 106.56 \\
\hline \hline Total & $\mathbf{7 0 9 . 1 5 8}$ & $\mathbf{3 1 1 . 1 7 5}$ \\
\hline
\end{tabular}

Sumber: Kecamatan Kramat Jati Dalam Angka, 2012

Untuk ini diperlukan pendampingan teknis pada masyarakat untuk membantu kesadaran mereka agar dapat secara mandiri meningkatkan kualitas tata lingkungannya sehingga mampu mendekati pola tata lingkungan yang aman, sehat dan nyaman serta kuat secara struktur menahan ancaman gempa, mengingat Indonesia merupakan wilayah rawan gempa yang berpotensi menimbulkan masalah yang sangat serius bahkan menelan korban jiwa yang sangat banyak seperti kejadian gempa di Palu tahun 2018 yang lalu (Hutabarat, 2019).

Kawasan Kelurahan Cawang yang berbatasan dengan letak kampus UKI merupakan wilayah strategis untuk dilakukan pembinaan oleh Prodi Teknik Sipil FT UKI. Namun untuk menjaga kontiunitas kesadaran masyarakat maka diperlukan strategi pelaksanaan yang tepat serta dilaksanakan secara berkelanjutan. "Untuk itu perlu mendampingi masyarakat supaya dapat secara mandiri meningkatkan kualitas kawasannya secara efektif dan berkelanjutan maka pendampingan akan dimulai dari tingkat RT, RW dan akhirnya seluruh kawasan Kelurahan Cawang dapat memperoleh manfaat dari pengabdian masyarakat yang dilakukan oleh Prodi Teknik Sipil" (Simanjuntak, 2020). Untuk mewujudkan bangunan rumah kuat, aman dan sehat di Kelurahan Cawang dimulai dengan pendampingan dan pembinaan terhadap para penduduk yang memiliki keahlian sebagai tukang.

Penataan sudah dimulai dari pelatihan pembuatan rumah sehat dan tahan Gempa dan terus berlanjut pada penataan kawasan ke sarana yang dapat diandalkan dalam pergerakan masyarakat di kelurahan ini diantaranya jembatan penghubung dan rumah contoh penduduk yang sering dimanfaatkan warga untuk keperluan sehari-hari mereka (Hutabarat, 2020). Selanjutnya dilakukan dirumah pos RW 10 melalui pelatihan kepada penduduk khususnya yang berprofesi sebagai tukang dengan harapan ini dapat berdampak pada kesadaran orang untuk menata lingkungan dan membuat bangunan yang sehat dan kuat termasuk terhadap gempa secara mandiri.

\section{METODE}

Metode pendampingan yang dilakukan mencakup beberapa cara seperti:

1) Penyuluhan yang bertujuan meningkatkan kesadaran serta pemahaman dalam rangka mendidik masyarakat,

2) Kegiatan yang menghasilkan produk inovasi tentang komponen material atau 
alat pendukung yang penting dalam membuat rumah sehat, kuat dan nyaman,

3) Pelatihan yang disertai dengan demonstrasi atau percontohan untuk menghasilkan keterampilan tertentu kepada kelompok masyarakat yang memiliki profesi sebagai tukang,

4) Melakukan mediasi dalam menyelesaikan masalah yang ada dalam masyarakat, e) Melalukan advokasi berupa pendampingan terhadap kelompok tukang yang sedang mengerjakan tugasnya.

Proses pelaksanaan kegiatan
pendampingan dilakukan sejak tahun
akademik 2017/2018 semester genap sampai dengan 2020/2021 semester gasal setiap semester secara berkelanjutan selama 3 tahun dengan fokus dan kelompok masyarakat yang berbeda di setiap semesternya.

Adapun tahapan yang dilakukan untuk setiap semester adalah sebagaimana terlihat pada Gambar 1 sebagai berikut:

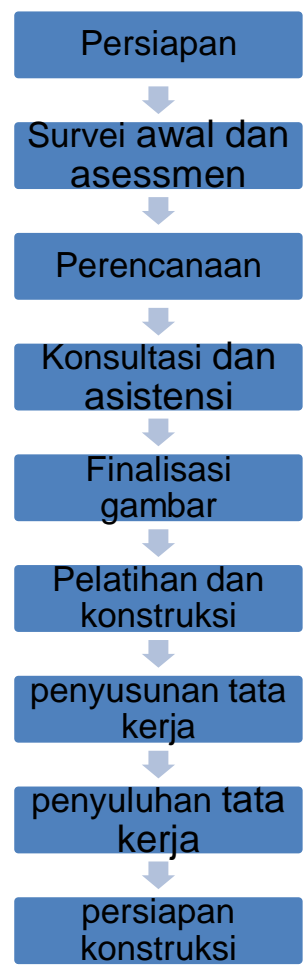

\section{Gambar 1. Skema Pendampingan} Masyarakat

Lokasi yang dipilih adalah wilayah permukiman di RT 01 RW 10 Jalan Ja'ani Nasir No.7 yang berbatasan langsung dengan kampus Universitas Kristen Indonesia. Program Pengabdian Kepada Masyarakat ini dilakukan oleh dosen dan mahasiswa di Prodi Teknik Sipil Fakultas Teknik UKI untuk merealisasikan keterlibatan perguruan tinggi dalam proses pembangunan yang dilakukan masyarakat baik dalam bentuk pendampingan maupun keterlibatan dalam proses fisik pembangunan.

\section{HASIL DAN PEMBAHASAN}

Munculnya permasalahan terkait pengelolaan lingkungan di Kelurahan Cawang akibat masih minimnnya pengelolaan manajemen penataan lingkungan yang baik di tingkat RT dan RW. Belum adanya kader-kader yang dapat membantu RT dan RW untuk membangkitkan kesadaran penduduk 
dalam menata lingkungannya merupakan salah satu penyebab munculnya permasalah tersebut sebagaimana terlihat pada Tabel 2.

Tabel 2. Permasalahan Manajemen Pengelolaan Lingkungan

\begin{tabular}{|c|c|c|c|c|}
\hline $\begin{array}{c}\text { Jenis } \\
\text { Permasalahan } \\
\end{array}$ & $\begin{array}{c}\text { Aspek } \\
\text { Permasalahan } \\
\end{array}$ & RT 01 & RW 10 & Solusi \\
\hline $\begin{array}{l}\text { Pelaksanaan } \\
\text { penyuluhan dan } \\
\text { pelatihan tentang } \\
\text { penataan } \\
\text { lingkungan sehat } \\
\text { dan pembuatan } \\
\text { rumah sehat dan } \\
\text { kuat terhadap gaya } \\
\text { gempa melalui } \\
\text { percontohan }\end{array}$ & $\begin{array}{l}\text { Masih banyak } \\
\text { wilayah di } \\
\text { lingkungan } \\
\text { kelurahan cawang } \\
\text { yang belum } \\
\text { memenuhi } \\
\text { standar } \\
\text { lingkungan dan } \\
\text { rumah sehat dan } \\
\text { kuat terhadap } \\
\text { gaya gempa }\end{array}$ & $\begin{array}{l}\text { Tidak adanya } \\
\text { anggaran dalam } \\
\text { pembinaan dan } \\
\text { pelatihan warga } \\
\text { secara berkala } \\
\text { untuk dapat } \\
\text { melakukan } \\
\text { penataan } \\
\text { lingkungan dan } \\
\text { rumah mereka } \\
\text { supaya aman } \\
\text { nyaman dan } \\
\text { sehat }\end{array}$ & $\begin{array}{l}\text { Tidak adanya } \\
\text { anggaran dalam } \\
\text { penyediaan } \\
\text { listrik jalan } \\
\text { menuju lokasi } \\
\text { dan tenaga ahli } \\
\text { perancangan } \\
\text { turbin penghasil } \\
\text { tenaga listrik }\end{array}$ & $\begin{array}{l}\text { Merancang dan } \\
\text { mengatur } \\
\text { bentuk } \\
\text { pelatihan } \\
\text { kepada } \\
\text { masyarakat } \\
\text { agar mampu } \\
\text { secra mandiri } \\
\text { menata } \\
\text { lingkungan dan } \\
\text { rumah yang } \\
\text { nyaman aman } \\
\text { dan sehat }\end{array}$ \\
\hline Manajemen & $\begin{array}{l}\text { Dana } \\
\text { Pelaksanaan }\end{array}$ & $\begin{array}{l}\text { Tidak adanya } \\
\text { dana dari } \\
\text { pemerintah } \\
\text { sehingga harus } \\
\text { dengan } \\
\text { mengoptimalkan } \\
\text { Swadaya } \\
\text { masyarakat }\end{array}$ & $\begin{array}{l}\text { Tidak adanya } \\
\text { dana dari } \\
\text { pemerintah }\end{array}$ & $\begin{array}{l}\text { Membentuk } \\
\text { manajemen } \\
\text { swadaya } \\
\text { mandiri untuk } \\
\text { menata } \\
\text { lingkungan dan } \\
\text { rumah yang } \\
\text { nyaman, aman } \\
\text { dan sehat }\end{array}$ \\
\hline
\end{tabular}

Sumber: Laporan PKM Prodi Teknik Sipil Semester Gasal 2020/2021

\section{Pendampingan Membuat Rumah Kuat Tahan Gempa}

Diantara beberapa wilayah di Dunia wilayah Indonesia termasuk daerah yang mempunyai tingkat resiko gempa yang tinggi. Data-data terakhir menunjukkan bahwa setiap tahun di Indonesia ada sepuluh aktifitas gempa bumi yang menimbulkan kerusakan yang cukup besar. Pada daerah pemukiman yang cukup padat, perlu adanya suatu perlindungan untuk mengurangi angka kematian penduduk dan kerusakan berat akibat goncangan gempa. Dengan menggunakan prinsip teknik yang benar, detail konstruksi yang baik dan praktis maka kerugian harta benda dan jiwa menusia dapat dikurangi.

Faktor utama yang menimbulkan bangunan mengalami kerusakan akibat gempa:

1) Faktor Lapangan (site)

Terdapat enam jalur gempa di Indonesia yang menentukan parameter dasar pembebanan alibat gaya gempa. Faktor ini akan lebih meningkat lagi jika kondisi tanah lunak karen tanah lunak mengalami pembesara goncangan akibat gempa. Misalnya Untuk Jakarta, pada zone 4 dan diatas tanah lunak koefisien beban rencana lateral adalah 
0,05 untuk struktur yang kaku seperti perumahan bertingkat rendah.

2) Faktor Bangunan

Umumnya bangunan yang fleksibel akan menerima beban gempa yang lebih kecil dibandingkan bangunan yang lebih kaku. Bangunan yang lebih ringan akan menerima beban gempa yang lebih kecil dari pada bangun yang berat dan bangunan yang kenyal akan menyerap beban gempa yang lebih kecil dari pada bangunan yang getas. Bangunan dari kayu digolongkan sebagai bangunan yang kenyal. Tetapi kekenyalan dapat diciptakan dalam struktur kayu dengan menggunakan alat penyambung yang kenyal pada tiap-tiap hubungan elemen stuktur kayu tersebut. Pada umumnya, sambungan dengan paku memberikan kekenyalan yang cukup

Beberapa hal praktis yang perlu dipahami oleh tukang pada saat membuat suatu bangunan adalah sebagai berikut:

\section{Denah sederhana dan simetris}

Kerusakan akibat gempa menunjukkan pada denah bangunan yang sederhana dan elemen-elemen struktur penahan gaya horisontal yang simetris akan lebi kuat karena efek torsi berkurang dan kekekuatan stukturnya merata.

\section{Bahan bangunan seringan mungkin}

Seringkali, oleh karena ketersediaan bahan bangunan ringan terbatas maka harus menggunakan bahan bangunan yang berat, tetapi sebaiknya memakai bahan bangunan yang ringan. Karena besarnya beban inersia gempa adalah sebanding dengan berat bahan bangunan. Sebagai contoh penutup atap genteng diatas kuda-kuda kayu menghasilkan beban gempa horisontal sebesar $3 x$ beban gempa yang dihasilkan oleh penutup atap seng diatas kuda-kuda kayu. Demikian juga dengan pasangan dinding bata menghasilkan beban gempa sebesar $15 x$ beban gempa yang dihasilkan oleh dinding kayu.

Dibuat sistim konstruksi penahan beban yg cukup

Gaya inersia gempa harus dapat disalurkan dari tiap-tiap elemen struktur dimulai dari struktur utama kemudian gayagaya ini mengalir ke pondasi dan ke tanah. Karena itu sangat penting struktur utama penahan gaya horizontal bersifat kenyal. Jika kekuatan elastis dilampaui, keruntuhan getas yang tiba-tiba tidak akan terjadi, selain itu telah direncanakan pada beberapa tempat tertentu terjadi leleh terlebih dulu.

Misalnya deformasi paku pada batang kayu terjadi sebelum keruntuhan akibat momen lentur pada batangnya. Sebagai contoh rumah sederhana dengan tiga hal utama yang menjadi perhatian yaitu struktur atap, struktur dinding dan pondasi sebagaimana terlihat pada Gambar 2,3,4,5 dan 6 dibawah ini: 


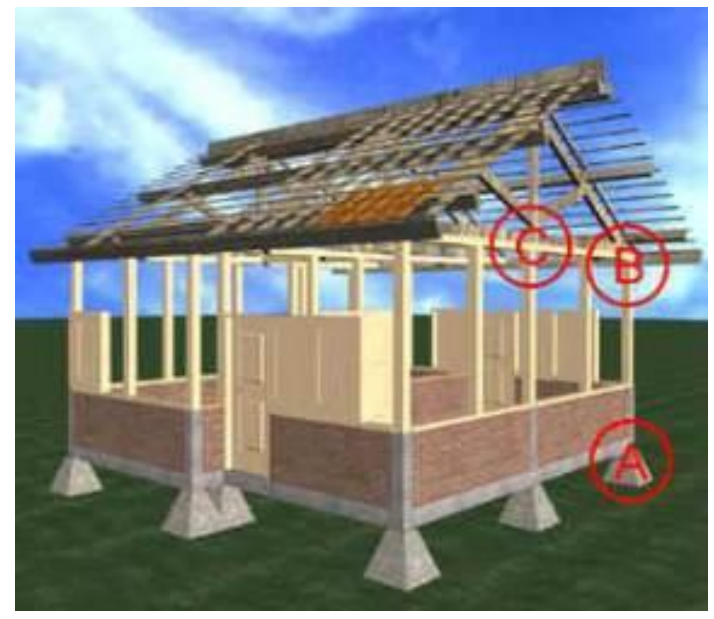

Gambar 2. Contoh Rumah Sederhana

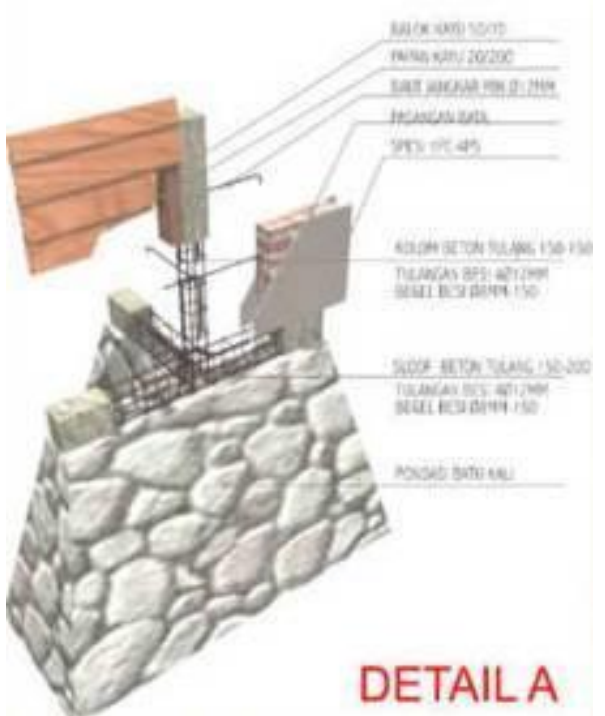

Gambar 3. Detil Pondasi

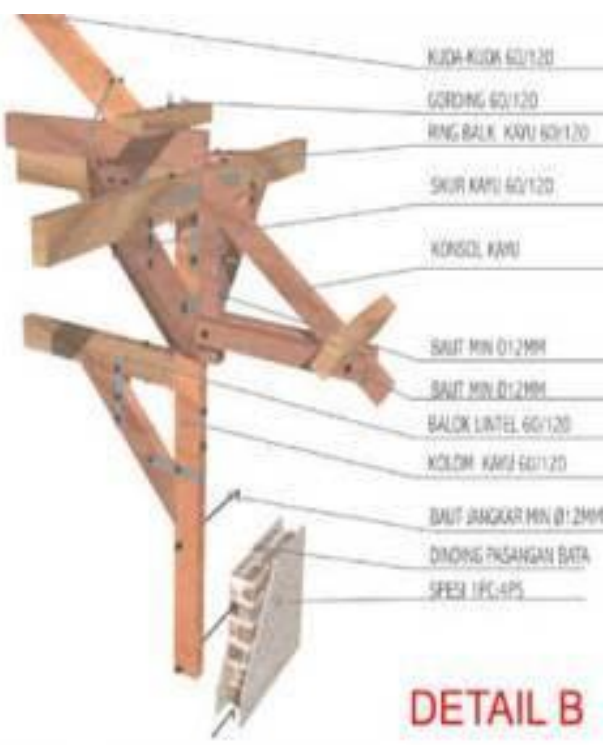

Gambar 4. Detil Struktur Dinding

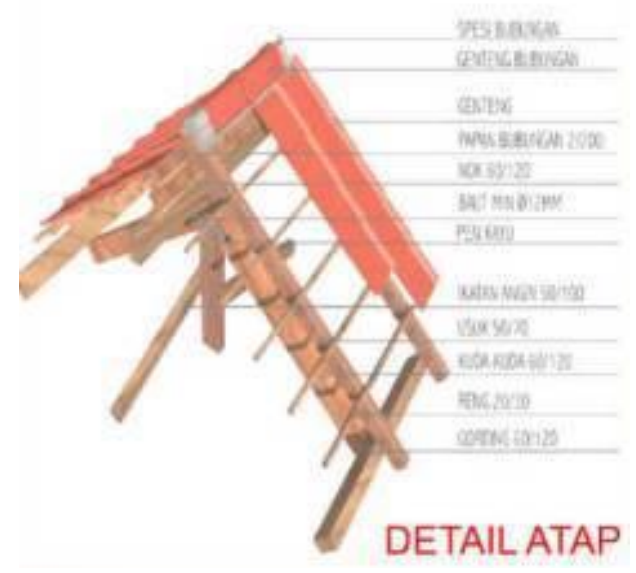

Gambar 5. Detil Pondasi

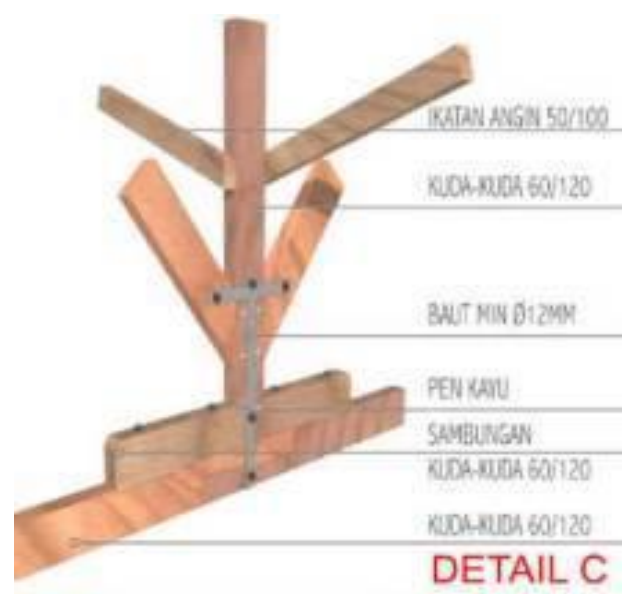

Gambar 6. Detil Struktur Dinding

\section{Struktur atap}

Jika tidak terdapat batang pengaku (bracing) pada struktur atap yang menahan beban gempa dalam arah $X$ maka keruntuhan akan terjadi Demikian Sebaliknya dengan pengaku tidak runtuh. Dengan catatan bahwa pengaku ini harus merupakan sistim menerus sehingga semua gaya dapat dialirkan melalui batang-batang pengaku tersebut kemudian dialirkan ke ring balok sebagaimana terlihat pada Gambar 7 dan Gambar 8 sebagai berikut: 


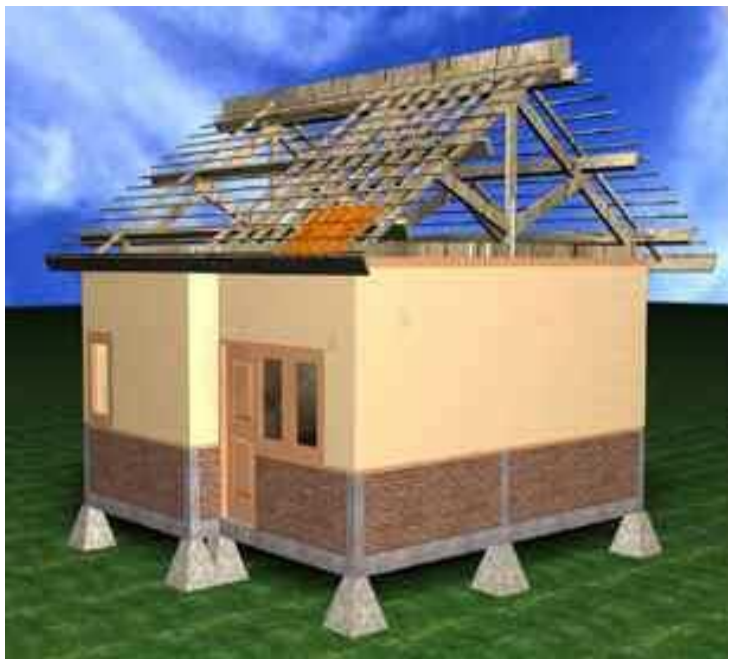

Gambar 7. Struktur Atap dengan Pengaku

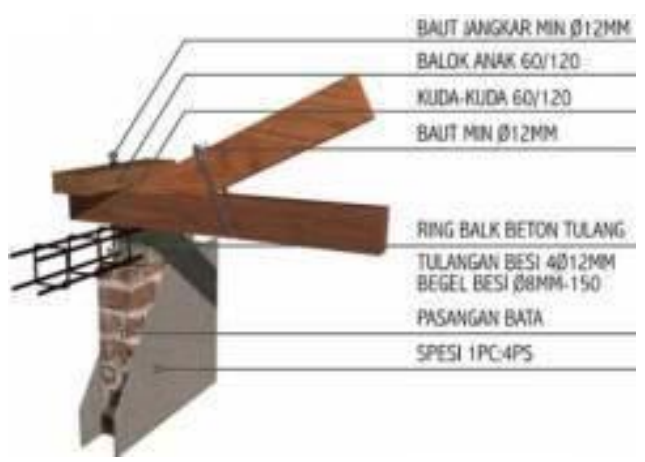

Gambar 8. Detil Atap dengan Pengaku

Gaya-gaya dari batang pengaku dan beban tegak lurus bidang pada dinding menghasilkan momen lentur pada ring balok seperti terlihat pada gambar diatas.

\section{Struktur dinding}

Beban dari ring balok harus ditahan oleh dinding. Gaya aksial pada ring balok dapat menimbulkan gerakan berputar pada dinding. Putaran ini ditahan oleh berat sendiri dinding, berat atap yang bekerja diatasnya dan ikatan sloof ke pondasi. Jika momen guling lebih besar dari momen penahannya maka panjang dinding harus diperbesar. Beban gempa pada arah $\mathrm{Y}$ ditahan sama seperti arah X. Dinding harus mampu menahan beban gempa yang searah dan tegak lurus dengan bidang dinding.

Dengan alasan ini maka dinding bata (tanpa tulangan) harus diperkuat dengan kolom praktis dengan jarak yang cukup dekat. Sebagai pengganti kolom praktis ini dapat dipakai tiang kayu.

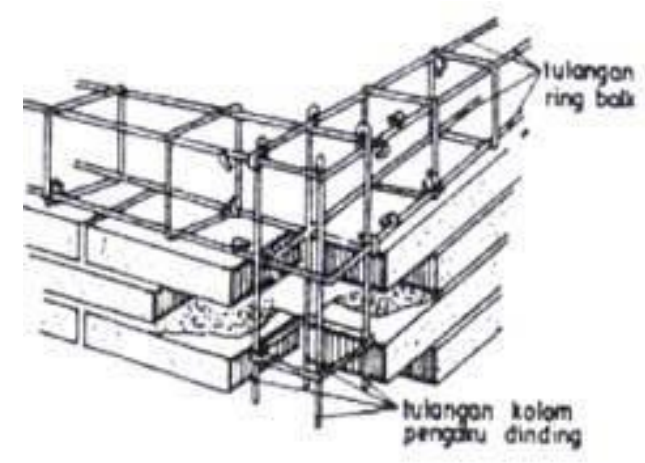

Gambar 9. Kolom Dinding dan Ring Balok Struktur pondasi

Struktur pondasi berperan untuk memindahkan beban gempa dari dinding ke tanah.Karena itu pondasi harus dapat menahan gaya tarik vertikal dan gaya tekan dari dinding. Sloof menerima gaya geser dan momen lentur sebagai jalur lintasan gaya terakhir sebelum gaya-gaya tersebut mencapai tanah.Akhirnya sloof memindahkan gaya-gaya datar tersebut ke pada tanah yang ditahan oleh daya dukung tanah dan tekanan tanah lateral.

Beberapa penggunaan batang pengaku untuk mencegah keruntuhan pada pondasi bisa dilihat pada Gambar 10 berikut: 


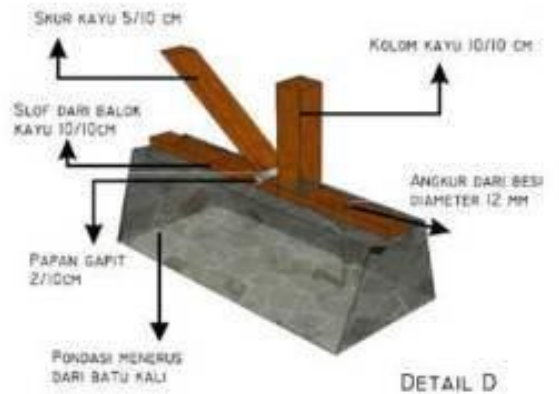

Gambar 10. Pengaku Pada Pondasi Menerus

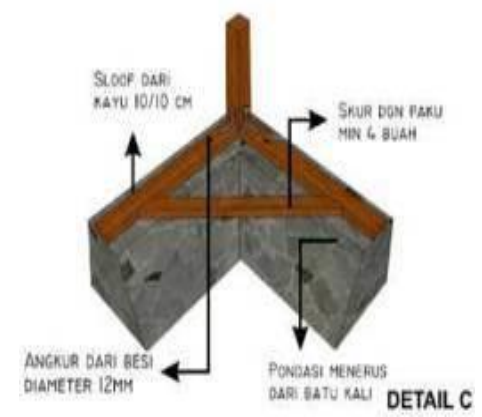

Gambar 10. Pengaku Pada Pondasi Sudut

\section{Pendampingan Membuat Septic Tank dan Sumur Bor}

Sebagai tempat penampungan dan pengolahan tinja sementara, keberadaan septic tank penting untuk mencegah penularan penyakit dan penyebaran bakteri. Selain itu, septic tank juga solusi mencegah timbunan tinja mencemari air dan lingkungan. Pemerintah juga sudah membuat peraturan tentang septic tank. Ketentuannya diatur dalam Peraturan Menteri Kesehatan (Permenkes) Nomor 3 Tahun 2014 tentang Sanitasi Total Berbasis Masyarakat (Wahyuningsih, 2016). Berdasarkan lampiran dalam Permenkes tersebut, setiap jamban perlu dilengkapi dengan fasilitas septic tank. Konstruksi tangki septik yang tidak sesuai standar berpotensi terhadap terjadinya pencemaran tanah dan air tanah oleh lindi limbah tinja dari tangki septik (Achmad, 2020)

Berbagai penelitian yang telah dilakukan dalam pembuatan septic tank yang berbasis swadaya masyarakat di beberapa daerah dapat digunakan sebagai pembanding (Setyo, 2021) dimana hanya 93\% masyarakat yang memiliki septic tank individu yang mayoritas tangki septik berupa konstruksi beton dan konstruksi batu bata. Sedangkan ukuran tangki septik sebagian besar adalah $2 m^{3}(47 \%)$. Karena itu konstruksi septic tank yang sesuai dengan SNI 03-2398-2002 relatif masih sangat rendah (<32\%). Untuk itu diperlukan penelitian lanjutan terkait septic khusus untuk Kelurahan Cawang.

Adapun septic tank adalah suatu bak kedap air yang berfungsi sebagai tempat penampungan limbah kotoran manusia (tinja dan urine). Bagian padat kotoran manusia akan tertinggal dalam tangki septik. Sedangkan bagian cairnya keluar dari tangki septik dan diresapkan melalui bidang atau sumur resapan. Jika tidak memungkinkan dibuat resapan maka dibuat suatu filter untuk mengelola cairan itu. Sedangkan menurut ketentuan Standar Nasional Indonesia (SNI) 2398:2017, septic tank harus kedap air. Septic tank juga perlu memiliki lubang kontrol, ventilasi, pipa masuk-keluar serta harus dikuras isinya, untuk dibuang dengan truk tinja secara reguler. Limbah dari septic tank itu dikirim ke Instalasi Pengolahan Lumpur Tinja (IPLT). Selain itu septic tank 
memiliki bagian penampungan dan pengolah air limbah dengan kecepatan aliran lambat.

Tujuannya memberikan kesempatan pengendapan benda padat agar terjadi penguraian menjadi bahan larut air dan gas. Air yang keluar dari septic tank harus dialirkan ke tempat pengolahan lanjutan yang bisa berupa tiga macam bentuk, sesuai dengan kondisi lokasi: Bidang resapan, sumur resapan pada daerah air tanah rendah Sistem penyaringan dengan up flow filter pada daerah air tanah tinggi Taman sanita pada daerah air tanah rendah dan air tanah tinggi SNI 2398:2017 pun mengatur jarak minimal yang aman antara lokasi tempat pengolahan septic tanc dengan sumur dan bangunan.

Secara teknis ukuran, jarak ke sumur resapan dan volume yang dibutuhkan untuk konstruksi septic tank dapat dilihat pada Tabel 3 dan Tabel 4 sebagai berikut:

Tabel 3. Persyaratan Ukuran Standar Septic Tank

\begin{tabular}{ccccc}
\hline $\begin{array}{c}\text { Jumlah } \\
\text { pengguna }\end{array}$ & $\begin{array}{c}\text { Volume } \\
\left(\mathbf{m}^{\mathbf{3}} \mathbf{)}\right.\end{array}$ & $\begin{array}{c}\text { Panjang } \\
(\mathbf{m})\end{array}$ & $\begin{array}{c}\text { Lebar } \\
\mathbf{( m )}\end{array}$ & $\begin{array}{c}\text { Tinggi } \\
(\mathbf{m})\end{array}$ \\
\hline 5 orang & 2,1 & 1,6 & 0,8 & 1,6 \\
10 orang & 3.9 & 2,1 & 1,0 & 1,8 \\
15 orang & 5,8 & 2,5 & 1,3 & 1,8 \\
20 orang & 7,8 & 2,8 & 1,4 & 2 \\
50 orang & 19,4 & 4,4 & 2,2 & 2 \\
\hline
\end{tabular}

Sumber: SNI 03-2398-2002 dan SNI 2398:2017

Tabel 4. Persyaratan Jarak Standar Septic Tank

\begin{tabular}{lc}
\hline \multicolumn{3}{c}{ Komponen } & Jarak (m) \\
\hline Jarak minimal sumur resapan septic tank dengan sumur air bersih & 10 \\
Jarak minimal aliran filter septic tank dengan sumur air bersih, & 5 \\
bangunan/rumah, dan sumur resapan air hujan & \\
Jarak minimal septic tank dengan sumur air bersih, \\
bangunan/rumah, dan sumur resapan air hujan \\
$\begin{array}{l}\text { Jarak minimal septic tank dengan sumur air bersih, } \\
\text { bangunan/rumah, dan sumur resapan air hujan }\end{array}$ & 1,5 \\
\hline
\end{tabular}

Faktor pengaruh jarak septic tank tersebut antara lain disebabkan oleh:

1) kondisi permukaan tanah dan sudut kemiringan tanah.

2) kedalaman air tanah, arah dan kecepatan aliran tanah, lapisan tanah yang berbatu dan berpasir. Lapisan pasir memerlukan jarak yang lebih jauh dibandingkan dengan lapisan tanah liat yang bersifat lebih kedap.

3) curah hujan tinggi memerlukan jarak sumur harus lebih jauh dari kakus.

4) jenis mikroorganisme seperti bakteri patogen lebih tahan pada tanah basah dan lembab seperti cacing dapat 
bertahan pada tanah yang lembab dan basah selama 5 bulan.

5) Frekuensi pemompaan jika makin banyaknya sumur maka laju aliran tanah menjadi lebih cepat untuk mengisi kekosongan tersebut.

Tabel 5. Pendampingan Teknis Pembuatan Rumah Sehat, Kuat dan Nyaman

\begin{tabular}{lllc}
\hline \multicolumn{1}{c}{ Bulan } & \multicolumn{2}{c}{ Frekuensi pendampingan } & Hasil pendampingan \\
\hline Maret 2020 & Tgl 6, 13, 20 dan 27 & 4 @ 3 jam & survey \\
April 2020 & Tgl 3, 10, 17 dan 24 & 4 @ 3 jam & perencanaan \\
Mei 2020 & Tgl 1, 8, dan 15 & 3 @ 3 jam & konsultasi dan asistensi \\
Juni 2020 & Tgl 5, 12, 19 dan 26 & 4 @ 3 jam & Finalisasi gambar \\
Juli 2020 & Tgl 3, 10, 17, 24 dan 31 & 5 @ 3 jam & penyusunan tata kerja \\
Agustus 2020 & Tg 7, 14, 21 dan 28 & 4 @ 3 jam & penyuluhan tata kerja \\
September 2020 & Tgl 4, 11, 18 dan 25 & 4 @ 3 jam & persiapan konstruksi \\
Oktober 2020 & Tgl 2, 9, 16, 23 dan 30 & 5 @ 3 jam & pelatihan dan konstruksi \\
November 2020 & Tgl 6, 13, 20 dan 27 & 4 @ 3 jam & pelatihan dan konstruksi \\
Desember 2020 & Tgl 4, 11, dan 18 & 3 @ 3 jam & pelatihan dan konstruksi \\
\hline \hline
\end{tabular}

Sumber: Laporan PKM Prodi Teknik Sipil Semester Gasal 2020/2021

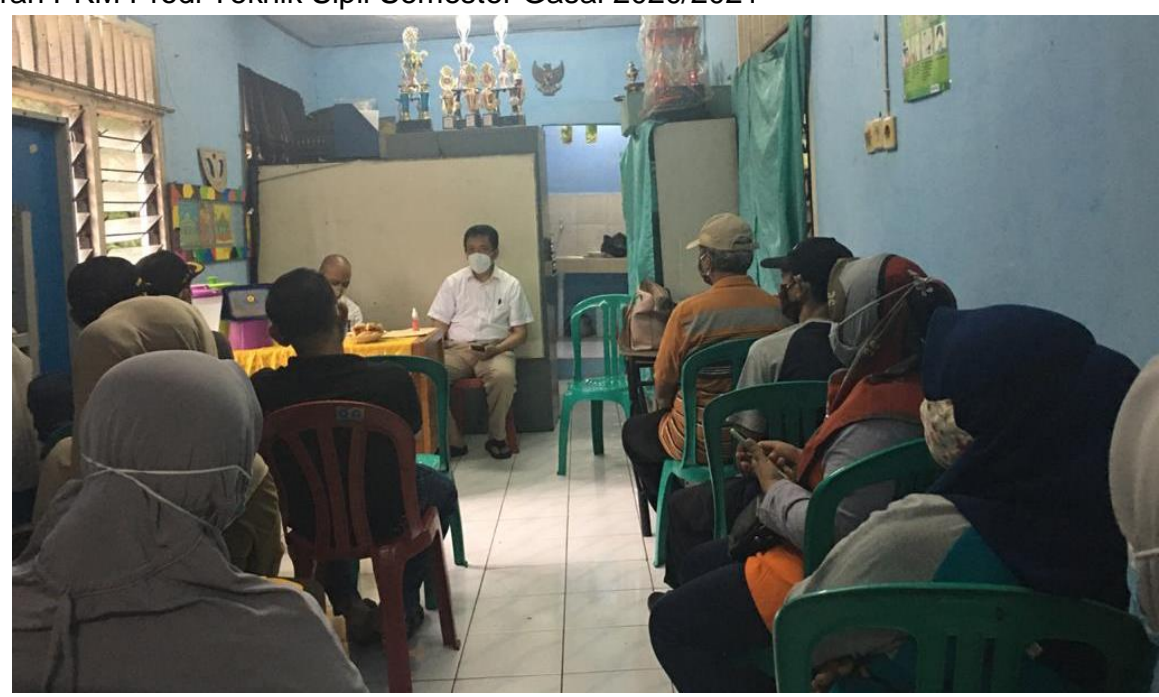

Gambar 11. Kegiatan Pendampingan Tim PKM Prodi Teknik Sipil FT UKI

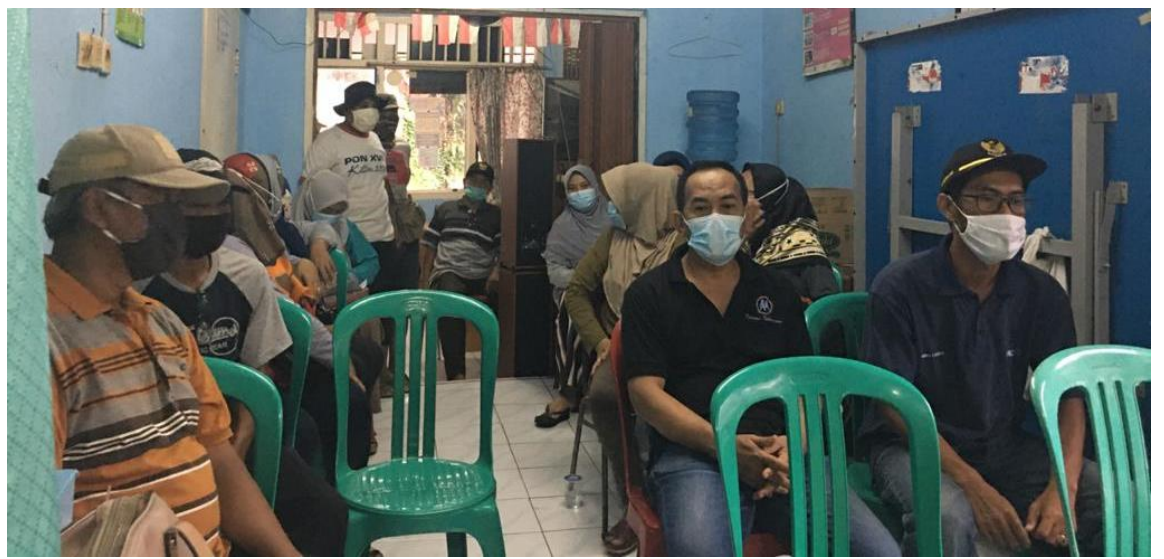

Gambar 12. Peserta Kegiatan Pendampingan Teknis 


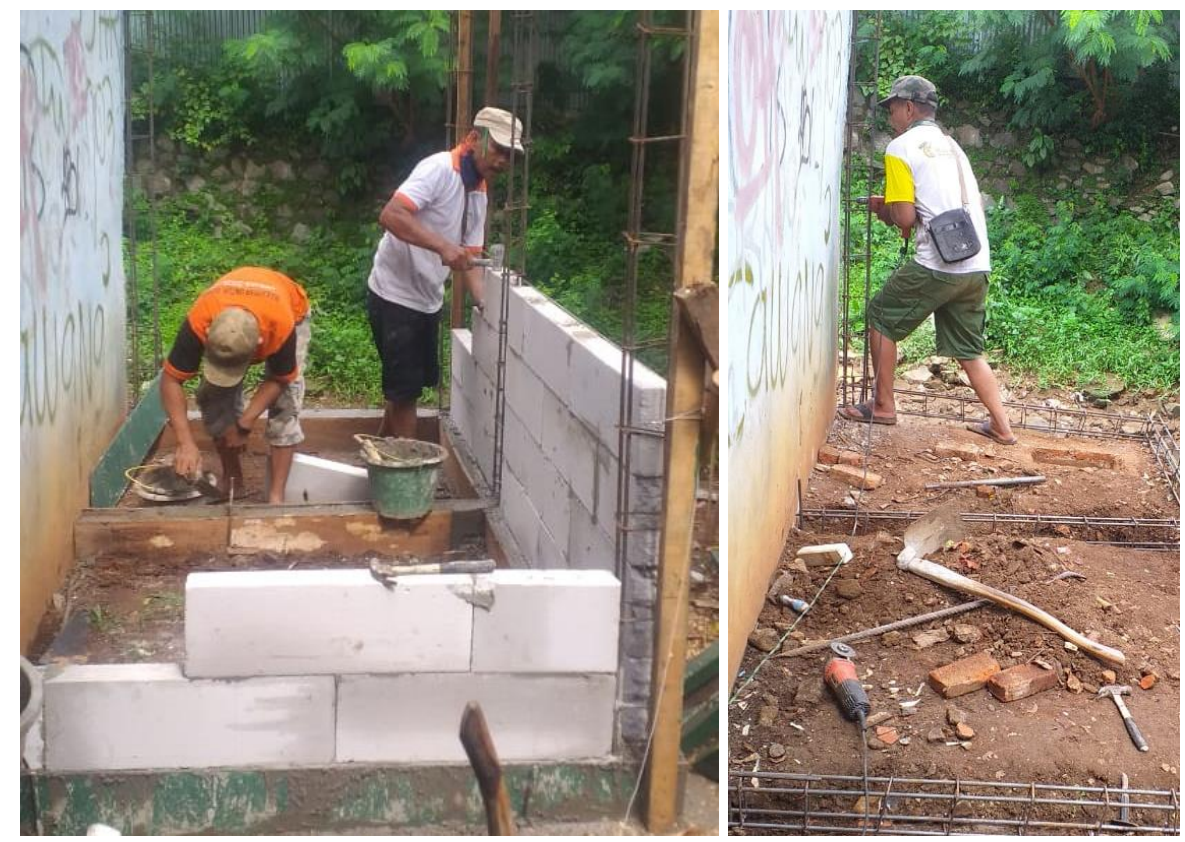

Gambar 13. Pendampingan Teknis untuk Tukang

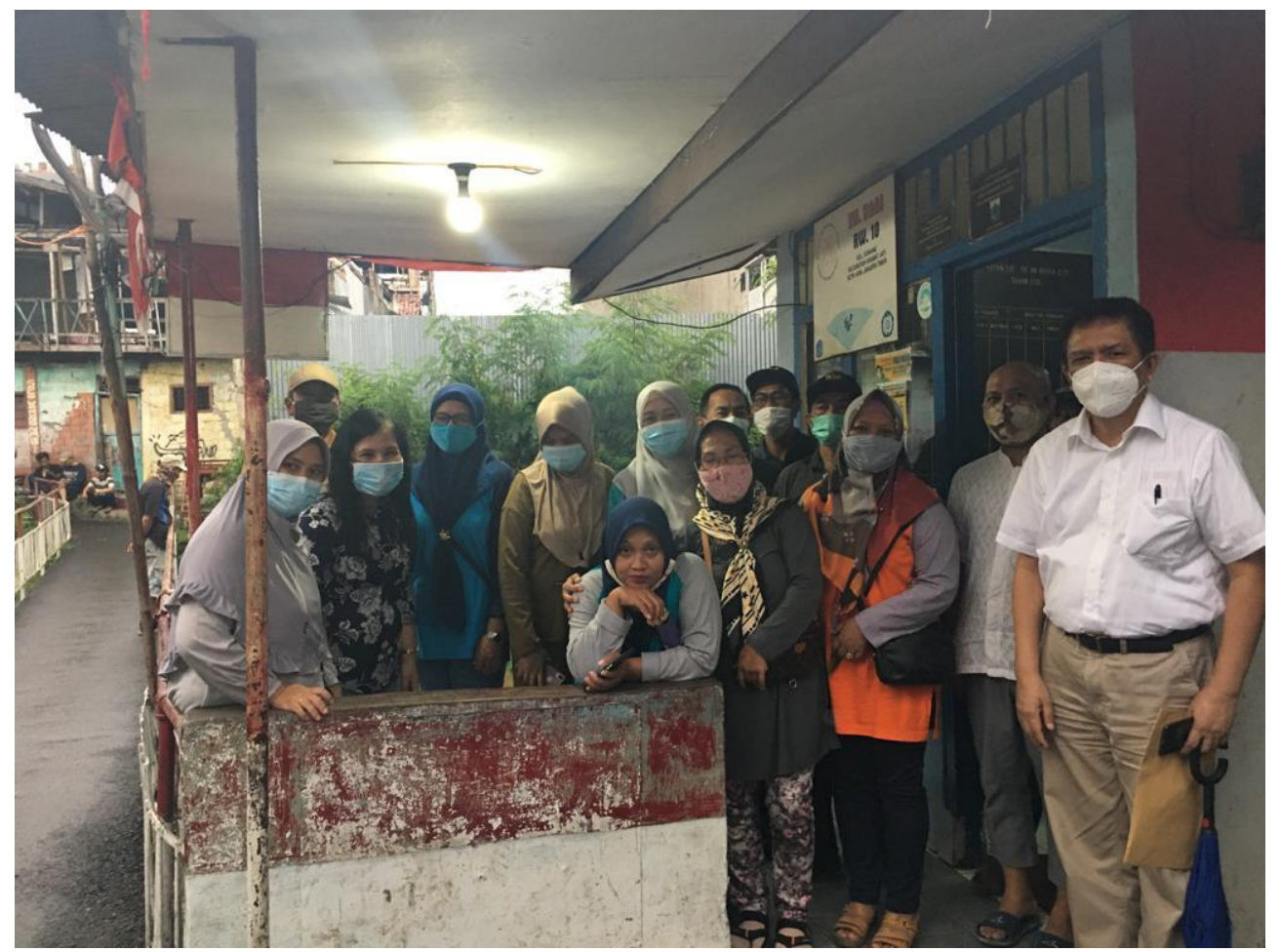

Gambar 14. Kegiatan Pendampingan Teknis di Tengah Pandemik Covid-19

Berbagai manfaat yang didapatkan dari kegiatan pendampingan teknis tersebut adalah:

1) Masyarakat memahami konsep dan pengertian kondisi lingkungan fisik yang aman sehat dan nyaman.
2) Masyarakat menyadari pentingnya penataan lingkungan masing masing secara mandiri supaya aman, nyaman dan sehat secara berkelanjutan.

3) Masyarakat memahami bahwa pekerjaan penataan lingkungan 
mereka secara fisik dapat berhasil jika dilakukan secara mandiri dengan gotong royong.

4) Pembinaan masyarakat secara berkelanjutan di kawasan kelurahan cawang sekaligus menjadi percontohan kawasan yang aman nyaman dan sehat bagi masyarakat di DKI Jakarta.

\section{KESIMPULAN}

Kegiatan pendampingan teknis pembuatan bangunan yang sehat, kuat dan nyaman RW 10 telah meningkatkan pemahaman masyarakat tentang penataan lingkungan di kawasan Kelurahan Cawang. Pendampingan teknis ini dilaksanakan selama total 120 jam yang dimulai dari survei, perencanaan, konsultasi dan asistensi, finalisasi gambar teknis, penyusunan tata kerja, serta persiapan pelaksanaan termasuk pelatihan tenaga kerja saat pelaksanaan. Proses konstruksi dilaksanakan dengan swadaya masyarakat sehingga terbangun kesadaran masyarakat untuk membangun, memelihara dan mengembangkan kegiatan penataan lingkungan yang berbasiskan kegiatan pada masyarakat itu sendiri.

\section{UCAPAN TERIMA KASIH}

Ucapan terimakasih kepada ketua RW 10 Bp Hamam yang telah memberikan kesempatan untuk melakukan survei dan asessmen untuk pembenahan lingkungan dan penataan bangunan yang sehat, kuat dan nyaman di wilayah RW 10 Kelurahan Cawang Kecamatan Kramat Jati Jakarta Timur.
Badan Pusat Statitstik Kota Jakarta Timur (2017). Kecamatan Kramatjati dalam Angka. Jakarta. 210-218.

Badan Pusat Statistik (2020), Kota Jakarta Timur Dalam Angka 2020, Katalog BPS: 1102001.3172, Badan Pusat Statistik Kota Jakarta Timur

https://metro.tempo.co/read/1430808/banjir15-meter-di-rw-05-kelurahan-cawangtak-kunjung-surut/full\&view=ok

Cahyani, B. P., Setyono, D. A., \& Purnamasari, W. D. (2019). HUBUNGAN TINGKAT PENERIMAAN MASYARAKAT DENGAN TINGKAT LIVABILITY PERMUKIMAN KAMPUNG DERET PETOGOGAN DAN KAMPUNG DERET KAPUK. Jurnal Tata Kota dan Daerah, 11(1), 11-20.

Eni, S. P. (2007). Perbandingan Pola Permukiman Dan Kondisi Lingkungan Daerah Aliran Sungai (DAS) Ciliwung Pada Kelurahan Bidara Cina Dan Tanjung Barat Di Jakarta. EMAS Jurnal Sains dan Teknologi, 17(3), 227-240.

Hutabarat, L. E., Mulyani, A. S., \& Simanjuntak, R. M. (2020). Peningkatan Pemahaman Masyarakat tentang Teknis Perbaikan dan Pelebaran Jembatan Penyeberangan Sungai Kecil di Kelurahan Cawang. JURNAL ComunitÃ Servizio: Jurnal Terkait Kegiatan Pengabdian kepada Masyarakat, terkhusus bidang Teknologi, Kewirausahaan dan Sosial Kemasyarakatan, 2(1), 339-351. 
Hutabarat, L. E., Simanjuntak, P., \& Tampubolon, S. (2019). Peningkatan Kesadaran Masyarakat terhadap Kerusakan Bangunan dan Lingkungan Pasca Gempa, Tsunami dan Likuifaksi di Palu Sulawesi Tengah. JURNAL ComunitÃ Servizio: Jurnal Terkait Kegiatan Pengabdian kepada Masyarakat, terkhusus bidang Teknologi, Kewirausahaan dan Sosial Kemasyarakatan, 1(2), 208-222.

Katoppo, M. L. (2011). Dampak

pemanfaatan ruang terbuka hijau

mandiri terhadap suhu dan

kenyamanan hunian (Studi Kasus:

Kampung Melayu dan Kampung UKI

Cawang, Jakarta Timur serta

Kampung Hijau Banjar Sari, Cilandak, Jakarta Selatan).

Laporan PKM Prodi Teknik Sipil FT UKI (2018), Pendampingan Teknis Pada Perbaikan Dan Pelebaran Jembatan Penyeberangan Sungai Kecil Di Jl. Haji Nazir Rt 01 Rw 10 Kelurahan Cawang. LPPM UKI, Jakarta

Maarif, S., \& Sari, D. A. P. (2020). THE CHARACTERISTICS OF URBAN COMMUNITIES IN THE DISASTER RESPONSE AREA (CASE STUDY: KELURAHAN CAWANG, EAST JAKARTA, DKI JAKARTA). Humanities \& Social Sciences Reviews, 8(1), 295-305.

Ningrum, S. S., \& Paramita, N. Penentuan Sistem Pengelolaan Limbah Domestik Berkelanjutan di Wilayah Padat Penduduk Bantaran Sungai Ciliwung
(Studi Kasus: Kelurahan Cililitan). Jurnal Presipitasi: Media Komunikasi dan Pengembangan Teknik Lingkungan, 17(3), 307-315. Nursyahbani, R., \& Pigawati, B. (2015).

Kajian Karakteristik Kawasan Pemukiman Kumuh di Kampung Kota (Studi Kasus: Kampung Gandekan Semarang). Jurnal Teknik PWK (Perencanaan Wilayah Kota), Vol.4 No.2. 2015. 267-281.

Rianda, A., \& Hilmah, S. (2020). Upaya Peningkatan Kesehatan Mental Melalui Konseling Pada Masyarakat Korban Banjir Kelurahan Cawang Jakarta Timur. Jurnal Pengabdian Masyarakat Bakti Parahita, 1(01).

Setyo, G. A., \& Radityaningrum, A. D. (2021, February). Profil Kondisi Eksisting Tangki Septik di Kota Kediri. In Prosiding Seminar Teknologi Perencanaan, Perancangan, Lingkungan dan Infrastruktur (pp. 380385).

Simanjuntak, P., Tambunan, E., \& Hutabarat, L. E. (2020). Pelatihan dan Bimbingan Teknis: Tata Letak Rumah Sehat, Sirkulasi Jalan Lingkungan dan Kelancaran Saluran Drainase di RW 10 Kelurahan Cawang.

Wahyuningsih, M. (2016). Implementasi Peraturan Menteri Kesehatan Nomor 3 Tahun 2014 tentang Sanitasi Total Berbasis Masyarakat (Studi Pada Program Stop Buang Air Besar Sembarangan di Desa Kandangan 
Jurnal Comunita Servizio

e-ISSN: 2656-677X

Volume 3, Nomor 1, Tahun 2021 Hal 526 - 541

Kecamatan Trucuk Kabupaten

Deret Rt 006/Rw 013 Keluarahan Tugu

Bojonegoro). Publika, 4(3).

Utara Kecamatan Koja Jakarta

Yani, A. S. (2014). Analisis Penjadwalan

Utara. Sustainable

Competitive

Proyek (Network) Penataan Kampung

Advantage (SCA), 4(1). 